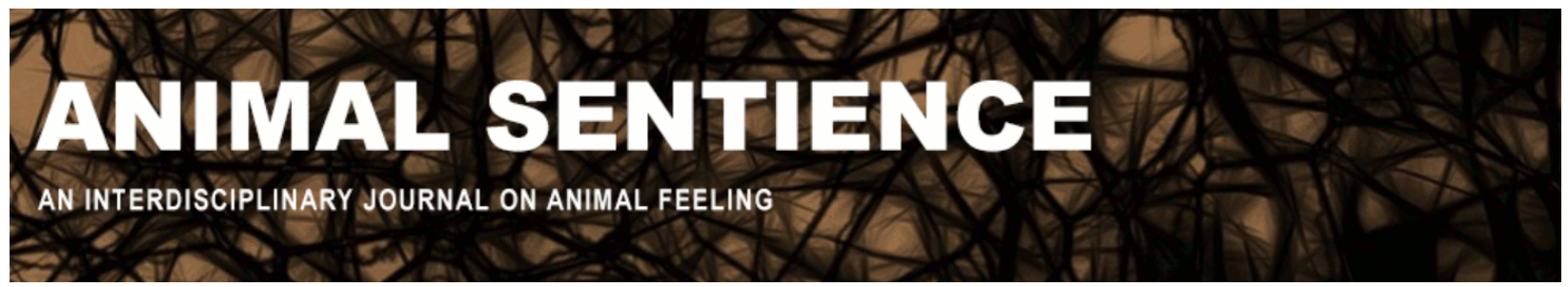

Urbanik, Julie (2020) Reinforcing boundaries does not contribute to change. Animal Sentience 30(27)

DOI: $10.51291 / 2377-7478.1661$

Date of submission: $2020-11-22$

Date of acceptance: $2020-12-06$ (c) 


\title{
Reinforcing boundaries does not contribute to change
}

Commentary on Wiebers \& Feigin on Covid Crisis

\author{
Julie Urbanik \\ Consultant and Scholar
}

\begin{abstract}
In prescribing blanket policy bans around wildlife and industrial animal farming as a protective response to the Covid-19 pandemic, Wiebers \& Feigin ignore the geographical context of their bans and reinforce problematic boundaries between nature and human society, human cultural groups, and animal-related industries.
\end{abstract}

\begin{abstract}
Julie Urbanik is a consultant and scholar. She holds a Ph.D. in Geography and is the co-founder of the Animal Geography Specialty Group of the Association of American Geographers. She is the author of the award-winning book Placing Animals and co-edited the first animal studies encyclopedia Humans and Animals: A Geography of Coexistence. Website
\end{abstract}

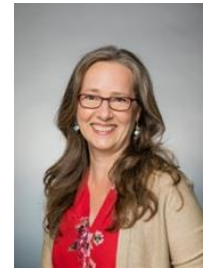

1. Introduction. That Covid-19 has brought a variety of animal-related issues to the forefront of people's minds around the world is, in my view, a huge opportunity for all of us who care about nonhumans, humans and the planet, so I appreciate the perspectives of neuroepidemiologists Wiebers \& Feigin (2020) (W\&F). In this commentary, I highlight what a geographic perspective brings to the table in order to map out the complexities involved in what W\&F propose as the simple solution of banning wildlife trade, wildlife markets, and factory farms. To this end, I will try to deepen the arguments made by Robbins (2020) about oversimplifying the issues with an explanation of animal geography and will then highlight three ways in which W\&F's thoughts reflect an uncontextualized approach to human-animal interactions that reinforces, rather than overcomes, existing problematic boundary-making mindsets.

Geography, as an academic field, explores the environmental and human processes that shape our planet. Animal geography is defined as the study of where, when, why and how nonhuman animals, as subjects in their own right, intersect with human societies (Urbanik 2012). Research covers the gamut of human-animal interactions through place and scale-based analyses of political, social, cultural, and economic conditions. Animal geographers are often interested in the production of boundaries (e.g., where/how are animals constructed as in/out of place, where/how have humans and animals been separated). These points of demarcation can help deepen our contextual understanding of human-animal relations and provide opportunities for new ways of encountering, treating, and living with nonhumans (Wolch \& Emel 1998; Gillespie \& Collard 2015).

In their analysis, W\&F, inadvertently or not, have obscured their own boundarymaking in three areas: the human/nature divide, political-cultural divides, and industry divides. This has afforded them an easier path to advocating direct bans than is warranted.

2. Reinforcing the Human-animal/nature Boundary. W\&F's suggestion to ban practices related to wildlife consumption, factory farming, and habitat destruction reinforces western notions of humans as separate from nature. These notions have come through western Christianity and western science (Merchant 2004) and ignore the decades of work by animal studies and environmental scholars challenging this very separation (Kalof \& Fitzgerald 2007). For example, recent work in animal geography (Lorimer 2020) explores how we are coming 
to understand - through a variety of fields - that humans are not even purely human but instead made human through the interaction of multiple species in our microbiomes. To argue that the solution to pandemics is to block ourselves off from encountering the living and nonliving entities that might harm us is a futile enterprise and one that goes against the ongoing evolutionary interactions that have shaped the planet and the human species.

3. Reinforcing Political-Cultural Boundaries. W\&F are quick to jump on the bandwagon of banning wildlife trade and wildlife consumption while (a) inadequately defining their terms and (b) reinforcing stereotypes and western privilege. Calling for a ban on "wet markets" that sell wildlife obfuscates the fact that wet markets are basically the same as farmer's markets in the U.S. (albeit the latter are without live wild or domesticated animals); in East Asia they are places of cultural connection and they provide economic livelihoods (Lynteris \& Fearnley 2020). Yes, people around the world eat wildlife and have done so since the beginning of humanity, yet framing the eating of wildlife by Asians or Africans as wrong is to set an artificial and condescending boundary between right and wrong cultures that smacks of a colonial mindset.

That Covid-19 has created what W\&F refer to as "global psychological distress" is true; however, what is also true is that the developed, largely western nations have been particularly distressed because we have been privileged enough not to have to live with daily worries about contracting any number of animal-based diseases. Malaria alone has caused people to live with distress and kills roughly 400,000 people a year in Africa (WHO 2019). Travel bans, lack of food supplies, empty shelves, economic distress, political chaos, and uncertainty about the future are issues faced by hundreds of millions of people every day. To act as if Covid-19 is new on the psychological front is to ignore these realities (Albaih 2020). Instead of condemning these people for surviving in their cultural landscapes, perhaps we in the north and west could learn from their resilience.

4. Reinforcing Hierarchical Economic Boundaries. What perhaps best epitomizes W\&F's selective boundary-making relates to their desire to ban a "USD74 billion wildlife farming industry" in China as well as the entire global factory farming industry without also calling for a ban on the multi-billion dollar global animal experimentation industry and, more specifically, a global ban on biolabs researching infectious diseases. That a biolab studying infectious diseases and diseases that can cross species would be banned would no doubt be anathema to W\&F because of the potential knowledge gained from the animal experimentation economy. Yet are they not petri dishes for future pandemics? Are they not locations of horrific treatment of nonhumans? As the response by Whitfort (2020) shows, the lack of animal welfare regulation in China is a problem, but it is only a reflection of a global animal experimentation industry that overwhelmingly treats animals as objects. The race for a Covid-19 vaccine is purported to require the massive use of species such as sharks (Bowman 2020) and yet W\&F fail to grapple with the logic of telling others they can't eat or farm nonhumans (wild or domestic) while exempting their own industry from scrutiny. Additionally, W\&F fail to contextualize that it was the U.S. animal sciences industry that brought us factory farms and pushed antibiotic use in the first place (Anderson 2019; Neo \& Emel 2017).

In conclusion, the need for dialogue and change in a post-Covid-19 world is real; however, as academics I believe we have a better chance of policy success if we provide paths through contextual complexity rather than reinforcing problematic cultural, political, and economic boundaries. 


\section{References}

Albaih, K. (2020) Our old normal. In: And we came outside and saw the stars again (I. Stavans, (Ed)). Restless Books: 108-112.

Anderson, J.L. (2019) Capitalist pigs: Pigs, pork and power in America. West Virginia University Press.

Bowman, E. (2020) A coronavirus vaccine could kill half a million sharks, conservationists warn. National Public Radio.

Gillespie, K. and R-C. Collard (Eds). (2015) Critical animal geographies: Politics, intersections, and hierarchies in a multispecies world. Routledge.

Kalof, L. and A. Fitzgerald (Eds.) (2007) The animals reader: The essential classic and contemporary writings. Berg.

Lorimer, J. (2020) The probiotic planet: Using life to manage life. University of Minnesota.

Lynteris, C. and L. Fearnley. (2020) Why shutting down Chinese 'wet markets' could be a terrible mistake. The Conversation.

Merchant, C. (2004) Reinventing Eden: The fate of nature in western culture. Routledge.

Neo, H. and J. Emel (2017) Geographies of meat: Politics, economy and culture. Taylor and Francis.

Robbins, J.A. (2020) Be wary of simple solutions to complex problems. Animal Sentience 30(16).

Urbanik, J. (2012) Placing animals: An introduction to the geography of human-animal relations. Rowman and Littlefield.

Whitford, A. (2020) China's lack of animal welfare legislation increases the risk of further pandemics. Animal Sentience 30(11).

Wiebers, D.O. and V. Feigin (2020) What the Covid-19 crisis is telling humanity. Animal Sentience 30(1).

(WHO) World Health Organization (2019) The world malaria report 2019.

Wolch, J. and J. Emel (Eds.) (1998) Animal geographies: Place, politics, and identity in the nature-culture borderlands. Verso. 